\title{
FORMAÇÃO DE PROFESSORES QUE ENSINAM MATEMÁTICA NO CONTEXTO DA CIBERCULTURA: ESTUDO EM UMA ESCOLA UCA
}

\author{
D. L. MAIA ${ }^{1}$, R. L. CARVALHO ${ }^{2}$, J. A. CASTRO FILHO ${ }^{3}$ e E. S. JUNQUEIRA 4 \\ ${ }^{1}$ Universidade Estadual do Ceará (UFC) \\ ${ }^{2}$ Universidade Federal do Cariri (UFCA) \\ ${ }^{3}$ Instituto UFC Virtual (IUVI) \\ dennysleite@gmail.com
}

Artigo submetido em fevereiro/2014 e aceito em setembro/2014

DOI: $10.15628 /$ holos.2014.2017

\section{RESUMO}

Nas últimas décadas, com o advento das tecnologias digitais, a sociedade tem passado por uma reconfiguração. As relações entre tais tecnologias e a cultura contemporânea é definida como Cibercultura. Nessa perspectiva, este trabalho tem como objetivo analisar de que forma as interações mediadas pelas tecnologias digitais contribuem para o desenvolvimento profissional do professor de Matemática, particularmente sobre o laptop educacional, do Projeto Um Computador por Aluno (UCA). Como método de pesquisa, utilizamos elementos da Pesquisa Colaborativa. A pesquisa foi realizada em uma escola de Ensino Fundamental, participante do Projeto UCA, localizada em Fortaleza-CE.

PALAVRAS-CHAVE: Aprendizagem colaborativa com suporte computacional, cibercultura, Projeto UCA, ensino de Matemática.

\section{MATH TEACHER TEACHING IN THE CYBERCULTURE CONTEXT: STUDY IN AN OLPC SCHOOL}

\begin{abstract}
In recent decades, with the advent of digital technologies, the society has been undergoing a reconfiguration. Relations between such technologies and contemporary culture is defined as cyberculture. In this perspective, this study aims to examine how the interactions mediated by digital technologies contribute to the professional
\end{abstract}

development of mathematics teachers, particularly on educational laptop, the Project One Computer per Student (UCA). As a research method, we use Collaborative Research elements. The research will be conducted in a primary school, participant UCA Project, located in Fortaleza-CE.

KEYWORDS: Computer Supported Collaborative Learning, Cyberculture, OLPC Project, Mathematics Teaching. 


\section{INTRODUÇÃO}

Desde 1997 diversos projetos são lançados no Brasil, a partir do Programa Nacional de Tecnologia Educacional (PROINFO), com objetivo de implantar e inserir tecnologias nas escolas públicas do País. Tais ações intencionam a criação de uma nova cultura na escola que integre os recursos multimidiáticos na dinâmica das ações pedagógicas.

Este foi o caso do Projeto Um Computador por Aluno (UCA) que previa, em sua fase piloto, iniciada em 2007, a distribuição para cada aluno, professor e gestor de escolas públicas, de um laptop educacional. Dentre as características dessa proposta de informatização das escolas estão a conectividade e a mobilidade desses equipamentos, que proporcionam e desvelam novas experiências e possibilidades pedagógicas, comparadas ao modelo dos laboratórios de informática educativa.

Desta feita, o Projeto UCA iniciou, oficialmente, no Brasil o modelo de informática educativa na situação um para um (1:1), que prevê um computador para cada usuário (WARSCHAUER, 2006). Nesse novo modelo de integração de tecnologias digitais nas escolas, os computadores fixos (desktops) são substituídos por dispositivos móveis (laptops, tablets, smartphones dentre outros), com conexão à internet, para serem utilizados de forma intensiva nas práticas educativas. Dessa maneira, o uso das tecnologias digitais deixa de ser um momento pontual e previamente planejado, para se tornar uma prática corrente de sala de aula, nos diversos espaços da escola e, inclusive, fora dela.

No modelo de informática educativa 1:1, as vantagens para os processos de ensino e de aprendizagem podem ser vislumbradas a partir do momento em que os sujeitos passam a utilizar os equipamentos visando a aquisição de informações e a construção de conhecimentos. Para tanto é necessário que professores e alunos percebam que tais equipamentos podem "ampliar seu acesso à informação, desenvolver habilidades de produção, adquirir novos saberes, expandir a sua inteligência e participar da construção coletiva do conhecimento" (BRASIL, 2007, p. 12), como destaca o documento que orienta o uso dos laptops do Projeto UCA.

Com ideia similar à proposta do referido Projeto estão os projetos que disponibilizaram tablets a professores do Ensino Médio, pelo Ministério da Educação (MEC) e o programa Um computador para cada Professor, da Secretaria de Educação do Município (SME) de Fortaleza, que doou um notebook para cada professor da rede. Em ambos os projetos a intenção é que os novos equipamentos proporcionem inclusão digital aos professores, além de propiciá-los outras fontes e materiais para planejar suas aulas. Tanto os tablets quanto os notebooks foram formatados visando o uso educacional, desde o sistema operacional que fornece links para acesso rápido a portais e objetos de aprendizagem mantidos pelo MEC. Tais recursos podem ser desencadeadores de aprendizagem, inclusive, colaborativa, caso os sujeitos tenham experiências de interação entre si.

Via de regra, essas vantagens das tecnologias digitais em Educação são relacionadas com os alunos. Todavia, os professores devem ser vistos como sujeitos que também têm muito a aprender com e sobre esses novos recursos, pela possibilidade de acesso a diferentes fontes de informação e interação com diversas pessoas, inclusive, colegas de profissão. 
Com o advento da internet, a informação se desloca entre espaços distantes em menor tempo. O espaço físico tem dado lugar ao desenvolvimento do ciberespaço e à constituição de redes de aprendizagem, onde as pessoas interagem, colaboram e aprendem juntas. Tais características têm contribuído para o desenvolvimento de experiências formativas mediadas pelas tecnologias digitais. Nesse novo contexto destacamos cursos com uma perspectiva formal, como é o caso da Educação a Distância (EaD) e informal, caracterizada pelo que tem se chamada de Educação Aberta e a Distância (EAD) e pelos Cursos Online Abertos Massivos (MOOC - Massive Open Online Courses) mais alinhados ao fenômeno da Cibercultura.

Cumpre lembrar que, por diversos motivos, as licenciaturas não são suficientes para a formação integral dos professores. Uma opção para complementar são os cursos de formação continuada e que podem se servir de elementos da EaD. A própria Lei de Diretrizes e Bases da Educação Nacional (LBDEN - № 9394/96) admite isso ao indicar, em suas Disposições Transitórias (Art. 87으, § 3으, alínea III), que o poder público deve "realizar programas de capacitação para todos os professores em exercício, utilizando também, para isto, os recursos da Educação a Distância". Nesse sentido, os cursos formais e informais mediados por tecnologias digitais podem contribuir para a formação docente inicial e continuada.

Considerando que os professores já dispõem de dispositivos para acesso à Educação online (BORBA; MALHEIROS; ZULATTO, 2008), a partir das citadas políticas de informatização, focaremos neste trabalho o uso de tecnologias digitais para professores em serviço da docência, portanto, a formação continuada. O processo formativo analisado envolveu conteúdos matemáticos relativos aos anos iniciais do Ensino Fundamental.

Pautamos a proposta formativa na perspectiva que entende a formação docente como um processo continuum (PIMENTA, 2009). Nesse sentido, o uso das tecnologias digitais favorecem a criação e ampliação de espaços de formação e possibilitam uma reflexão compartilhada independente de tempo e espaço físico. Com essa proposta, o processo de reflexão da prática não deve mais ficar limitado ao professor solitário, como é a prática da cultura escolar tradicional. Com o suporte das tecnologias digitais agora o professor pode compartilhar e discutir com seus colegas sua prática, numa perspectiva de desenvolvimento profissional. Para tanto as ações de colaboração, interação, compartilhamento, marcas da Cibercultura, são fundamentais para aquela proposta formativa.

Portanto, no que se refere ao professor, aqueles projetos de disponibilização de tecnologias digitais podem ressignificar a cultura de formação docente, pois são os meios para adentrar na Cibercultura. Desta feita, além de disponibilizar computadores aos professores, é relevante conhecer se e como eles têm utilizado tais equipamentos para o desenvolvimento de sua profissão. Como alerta Kenski (2013, p. 9) mesmo com a presença das tecnologias digitais nos espaços escolares à disposição dos professores existe o "problema do desencontro entre a formação do docente - centrada na sua atuação em espaços presenciais formais de escolarização - e as necessidades de habilidades, atitudes, valores e, sobretudo, conhecimentos que os novos espaços profissionais demandam".

Ao falarmos de lacunas formativas de professores nos preocupamos, para este trabalho, com aqueles professores que ensinam Matemática nos primeiros anos de escolarização. Prioritariamente formados nos cursos de Licenciatura em Pedagogia, esses profissionais da Educação, denominados Pedagogos, são responsáveis pela apresentação dos conceitos de todas 
as disciplinas às crianças. Dentre essas disciplinas, está a Matemática a qual esses professores carregam dificuldades e lacunas formativas tanto no que diz respeito aos conteúdos, como didáticos (BARRETO, 2007; NACARATO, PASSOS, MENGALI, 2010; MAIA, 2012). De acordo com estudo de Maia e Barreto (2013), estudantes de Pedagogia possuem reduzido espaço formativo para o ensino da Matemática com uso de tecnologias digitais. Tal deficit acarreta numa visão limitada de estratégias do uso desses recursos, cada vez mais presentes na escola, na disciplina com maiores índices de dificuldade durante a Educação Básica.

Diante desse quadro, o objetivo desse trabalho é analisar de que forma as interações mediadas pelas tecnologias digitais contribuem para o desenvolvimento profissional do professor que ensina Matemática com o laptop educacional. Como objetivos específicos, temos: caracterizar o perfil desses professores a partir do contexto da Cibercultura e analisar como utilizam e interagem com ferramentas digitais para o ensino de Matemática em uma perspectiva colaborativa.

Este trabalho, recorte de uma pesquisa de Doutorado em Educação Brasileira, analisará as experiências formativas colaborativas utilizadas por pesquisadores e professoras acerca de conteúdos matemáticos dos anos iniciais do Ensino Fundamental. Esta pesquisa tem natureza qualitativa e como referencial metodológico tomamos elementos da Pesquisa Colaborativa pois não nos interessamos apenas entender a natureza do trabalho desenvolvido pelo professor, mas igualmente pela formulação de alternativas de formação em serviço (IBIAPINA, 2008), neste caso com suporte de ambientes virtuais. A pesquisa foi realizada em uma escola de Ensino Fundamental, participante do Projeto UCA, localizada em Fortaleza-CE, com duas professoras que ensinam Matemática em turmas de 5 ano do Ensino Fundamental.

A pesquisa aconteceu entre os meses de setembro e novembro de 2013. Os dados coletados são provenientes de um formulário online aplicado às professoras no início do processo formativo, participação em fóruns e ferramentas colaborativas da web. A seguir, passamos a discutir o texto que está estruturado em uma seção teórica e resultados e discussões dos dados coletados.

\section{APRENDIZAGEM COLABORATIVA ENTRE PROFESSORES QUE ENSINAM MATEMÁTICA: POSSIBILIDADE DE FORMAÇÃO NO CONTEXTO DA CIBERCULTURA}

A formação contínua é concebida e vinculada com a prática do professor. Para Lima (2001, p. 45) a referida formação "é o processo de articulação entre o trabalho docente, o conhecimento e o desenvolvimento profissional do professor, enquanto possibilidade de postura reflexiva dinamizada pela práxis". Este processo formativo tem como referência o próprio trabalho docente, refletido a partir da relação teoria e prática. Como o ponto de partida e de chegada é a própria ação e reflexão sobre a prática docente, evidencia-se um contínuo processo formativo.

Concordamos com Silva e Barreto (2012, p. 77) ao pontuarem sobre a importância da formação continuada para professores que ensinam Matemática. De acordo com as autoras:

Em razão de problemas na formação inicial para o trabalho com a Matemática, ao professor resta aprender em sua formação continuada. Entende-se este processo não apenas como constituído pelos cursos de capacitação, mas também pelo que 
é vivenciado na prática de ensino. O professor necessita aprender muito do que ele deve ensinar, muitas vezes com os próprios alunos, com os livros didáticos, com colegas de trabalho, ou seja, os professores estão em constante busca de saberes e práticas.

Além das interações a que as pesquisadoras apontam, compreendemos e destacamos aquelas desveladas e mediadas com auxílio de tecnologias digitais. Por meio do acesso à internet, os professores podem buscar fontes de informação, tais como sites, enciclopédias, bibliotecas, grupos de pesquisa dentre outros; além de interagir com diversas pessoas, inclusive outros professores, dentro e fora da escola, com auxílio de redes sociais e comunidades virtuais de aprendizagem. $\mathrm{O}$ acesso e a apropriação dos bens culturais de forma livre por professores pode criar uma atmosfera favorável a uma nova cultura docente, apoiada nas características da Cibercultura (LÉVY, 1999).

Podemos definir Cibercultura como "produto social e cultural da sinergia entre a socialidade estética contemporânea [...] e as novas tecnologias" (LEMOS, 2010, p. 88). O autor complementa enfatizando como principal característica da Cibercultura "uma atitude social de apropriação criativa (vitalista, hedonista, presenteísta) das novas tecnologias." (IBDEM, p. 259). Levy (1999) pontua a Cibercultura como um "movimento social" que nasceu no meio dos jovens, da cultura das ruas e do imaginário ciberpunk, jovens que se opunham à cultura social vigente, focando as tecnologias digitais, o poder midiático, político e econômico.

Do ponto de vista de Oliveira (2003) vivenciamos um processo de transição de um paradigma conservador/dominante para um paradigma emergente, cujas bases são a crítica ao positivismo e a observância das questões sociais emergentes, um paradigma científico-social que integra saberes complexos numa rede interativa e intertextual, a qual Castells (1999) denomina de "Sociedade em Rede". Essa rede interconectada, ligando "Todos e Todos", Lemos (2010) chama de ciberespaço. Tal interpretação é baseada na perspectiva de Levy $(1999$, p. 137) que define ciberespaço como:

[...] um sistema complexo onde reina a interdependência entre o macrossistema tecnológico (a rede de máquinas interligadas) e o microssistema social (a dinâmica dos usuários), construindo-se pela disseminação da informação, pelo fluxo de dados e pelas relações sociais aí criadas.

A internet, seus sites e redes sociais utilizados com frequência pelos professores fora da escola, devem ser vistos e apropriados como ferramentas úteis à sua profissão. Pinheiro (2013) relata um curso informal de conceitos matemáticos explorados nos anos iniciais da escolarização, via Facebook, que interessou a mais de 15 professores. Percebemos assim que os professores estão procurando e refazendo o uso das tecnologias digitais que dispõem. Nesse sentido, Lemos (2010, p. 239), observa que:

A apropriação tem sempre uma dimensão técnica (o treinamento técnico, a destreza na utilização do objeto) e uma outra simbólica (uma descarga subjetiva, o imaginário). A apropriação é assim, ao mesmo tempo, forma de utilização, aprendizagem e domínio técnico, mas também forma de desvio (desviance) em relação às instruções de uso, um espaço completado pelo usuário na lacuna não programada pelo produtor/inventor, ou mesmo pelas finalidades previstas inicialmente pelas instituições. 
$\mathrm{Na}$ perspectiva do desviance, apontada por Lemos (2010), devem ser utilizadas as tecnologias digitais pelos professores. Estes devem entender tais equipamentos para além do que está posto: a inclusão digital dos alunos. A partir de usos que já fazem desses equipamentos para o seu dia a dia, atividades laborais ou mesmo de entretenimento, os docentes devem se apropriar de outras possibilidades que podem se servir desses artefatos, que talvez mesmo as instâncias macros e superiores a eles não tenham clareza. É compartilhar fatos de sua prática nas redes sociais, em espaços onde seus pares poderão ver, comentar, compartilhar e contribuir para uma discussão e reflexão.

Essas experiências demandam, além de equipamentos informáticos, como os laptops educacionais com conexão a internet, ambientes virtuais em que os sujeitos possam se comunicar e partilhar informações e produções. A utilização de ambientes colaborativos de aprendizagem favorece a criação das redes de aprendizagem. Além das ferramentas da web 2.0, como blogues e wikis, existem ambientes criados especificamente para essa finalidade, como os ambientes virtuais de aprendizagem. Tais ferramentas têm desvelado a criação de ambientes colaborativos de aprendizagem, significativos para a constituição de práticas colaborativas, mediadas por ferramentas digitais, a qual Stahl, Koschmann e Suthers (2006) denominam de Aprendizagem Colaborativa com Suporte Computacional. De acordo com esse autores, nesse processo de aprendizagem colaborativa:

[...] os indivíduos estão envolvidos como membros do grupo, mas as atividades nas quais eles estão engajados não são atividades de aprendizagem individual, mas sim nas interações do grupo, como negociação e compartilhamento (STAHL, KOSCHMANN, SUTHERS, 2006, p. 3)

Acesso amplo a equipamentos como os laptops oportunizam ao professor a participação em ambientes colaborativos de aprendizagem. É possível que muitos professores já se sirvam disso, mas ainda são experiências isoladas e pouco difundidas. Como destacam Mesquita e CastroFilho (2012, p. 3): "O uso das tecnologias digitais se consubstancia pelo sentido que os interagentes fazem delas. (...) o compartilhamento de conhecimento e sua construção na web requer interesse intrínseco dos sujeitos em fazê-los". A tecnologia, per si, não garante que as interações entre os sujeitos promovam aprendizagem. São necessárias ações formativas que favoreçam e fomentem tais experiências.

Isto é que identificou Chagas (2002) em seu estudo. Segundo a pesquisadora, mesmo com disponibilidade dessas tecnologias, ainda há a dificuldade para a efetivação de redes de aprendizagem colaborativa, que vão além de problemas técnicos e operacionais, ao interesse, ou mesmo conhecimento, dos participantes em práticas dessa natureza. A esse respeito Kenski (2013) esclarece que há uma forte cultura entre os professores, mesmo entre aqueles que atuam com ensino online, para o trabalho de forma solitária.

No caso da Matemática, Silva e Barreto (2013, p. 78), destacam que os professores que ensinam a disciplina:

[...] recorrem, na maioria das vezes, ao livro didático como o grande suporte de conhecimentos. Tal ação, porém, não garante o domínio pleno dos conteúdos, tampouco abre possibilidades para a criação de metodologias e uso de representações diversificadas, necessários à superação das dúvidas apresentadas pelos alunos. 
Como fatores preponderantes para o desenvolvimento dessa nova cultura de uso das tecnologias digitais à favor de experiências de aprendizagem colaborativa estão a maneira como os professores têm feito uso dos dispositivos móveis que possuem para aprender sobre a docência; e as reais condições de trabalho e de formação desse grupo de professores para a criação de ambientes de aprendizagem colaborativa.

A escola deve manter uma cultura de desenvolvimento desse trabalho colaborativo junto aos professores sem e com o uso das tecnologias digitais. Para que ocorra aprendizagem colaborativa todos os sujeitos devem se sentir motivados para construir o conhecimento juntos. A ideia de coletividade é bastante evidente pois um indivíduo ajuda o outro para que alcance um objetivo.

Neste sentido, é necessário uma cultura colaborativa entre os professores e as tecnologias podem contribuir para evitar o isolamento e a realização de atividades individuais e promover o compartilhamento de saberes e experiências. Pesquisas no sentido de conhecer como efetivar tais práticas podem contribuir para efetivação dessas redes de aprendizagem colaborativa de professores, com suporte de tecnologias digitais. Para tanto, conhecer o perfil desses professores e como fazem uso desses ambientes é fundamental, como passamos a discutir a seguir.

\section{PERFIL DAS PROFESSORAS PARTICIPANTES, RESULTADOS E DISCUSSÕES}

As professoras participantes da pesquisa são lotadas em uma escola UCA no município de Fortaleza ${ }^{1}$. Elas têm, em média, 15 anos de magistério e possuem vínculo empregatício com a rede pública municipal entre 10 a 15 anos e sempre atuaram nos primeiros anos de escolarização. Atualmente, estão trabalhando, apenas, com turmas de 5ㅇan ano do Ensino Fundamental, lecionando as disciplinas de Matemática, Português e História².

No que diz respeito à formação inicial, uma professora (P1) possui o curso pedagógico na modalidade normal, formação mínima admitida pela LDBEN para atuação nessa área e a outra (P2) possui graduação em Pedagogia. Destacamos que nenhuma delas tiveram, em sua formação inicial, experiências e disciplinas que explorassem as tecnologias digitais. Todavia, ambas concluíram a Formação Brasil do Projeto UCA, caracterizando assim a formação continuada nessa área. Atentamos ainda para o fato de que essa formação utilizou componentes a distância, o que pode contribuir para experiências futuras de maneira semelhante como a proposta neste estudo.

Destacamos que embora ambas tenham concluído esse curso uma delas (P2) assumiu que nunca utilizou um ambiente virtual para discutir o uso pedagógico de tecnologias digitais com outros professores. Evidenciamos com esse dado que mesmo o acesso a tecnologias digitais e cursos de formação não são suficientes para uma mudança cultural das professoras no que diz respeito ao uso de tais recursos para desenvolver sua profissão.

As professoras têm acesso a computador e internet em casa e no trabalho e utilizam tais tecnologias digitais, fora de sala de aula, para entretenimento, pesquisa e estudo, além de planejar suas aulas. Apesar de não termos indícios de uma verdadeira mudança na cultura docente, identificamos elementos que indicam a inserção das tecnologias digitais na prática docente, ainda

\footnotetext{
${ }^{1}$ A fim de garantir o anonimato das professoras serão utilizados os protocolos P1 e P2.

${ }^{2}$ Decorrência do $1 / 3$ de planejamento da Lei do Piso.
} 
que de forma inicial. Isso é reforçado com a avaliação que dão à sua apropriação do laptop em um fórum de discussão no ambiente colaborativo. Ao avaliarem seu domínio pedagógico do laptop educacional que dispõem, numa escala de 1 a 5, optaram por 3 e 4. Ao justificarem essa informação, colocaram que:

Ainda tenho muita dificuldade em dominar essa ferramenta, mas tenho procurado melhorar, porém preciso de constante ajuda. [P2 - avaliou sua apropriação com 3].

Tenho habilidade no uso da máquina e pesquiso atividades que possam agregar valor às minhas aulas, nem sempre dão certo mas devido a outras causas, como acesso à internet e alguns laptops que precisam de manutenção. [P1 - avaliou sua apropriação com 4].

Essas caraterísticas indicam que as professoras têm perfil de usuárias de tecnologias digitais que podem favorecer à experiências de colaboração com suporte computacional. Contudo, ainda precisam de suporte que estão além do aspecto pedagógico, que estão no nível de conhecimentos técnicos inerentes ao campo da informática.

Tomando como análise as participações no ambiente virtual, iniciamos com as interações realizadas em dois fóruns de discussão. No primeiro, realizado no período de 11 a 31 de outubro de 2013, foram 14 participações entre professoras e pesquisadores. Este fórum, intitulado "Reflexões sobre as aulas", objetivou uma reflexão entre os participantes acerca de duas aulas realizadas durante o período que fora planejada de forma colaborativa via documento de texto do Google Drive.

O objetivo da aula foi "resolver situações problemas que envolvam o uso do dinheiro". Para tanto, foi proposto que os alunos trouxessem encartes de supermercados para a sala para que simulassem a compra de uma lista de produtos e, evidentemente, calculassem o valor a ser gasto. Uma das professoras sugeriu ainda que, antes dessa atividade, fosse explorada a leitura do um livro "Como se fosse dinheiro", da autora Ruth Rocha.

Após a experiência com os encartes os alunos vivenciaram uma atividade semelhante com uso do objeto de aprendizagem (OA) Supermercado Virtual, desenvolvido por um grupo da Universidade São Francisco (UNIFRA). Esse OA foi conhecido, escolhido e acessado a partir do repositório Objetos de Aprendizagem para Matemática (OBAMA), elaborado pelo Grupo de Pesquisa Matemática e Ensino (MAES) da Universidade Estadual do Ceará (UECE). As professoras consideraram que o OA poderia ir além da experiência com os encartes pois simularia uma situação de compra e trocas monetárias, conversão de unidades (gramas para quilogramas) e adição e multiplicação de valores e comparação de quantidades.

Observe-se que, mesmo assumindo que ainda tinham dificuldades, de ordem pessoal ou técnica, com o uso de recursos digitais, as professores planejaram de forma colaborativa a aula. Além de usarem materiais didáticos digitais, como o OA, utilizaram uma ferramenta colaborativa para o planejamento da aula - Documento de texto do Google Drive -, e refletiram sobre a experiência no fórum do ambiente colaborativo. Assim, depreendemos que com auxílio dos pesquisadores, as professoras são capazes de ir além do uso que estariam, ou achariam, aptas a fazer das tecnologias digitais que dispunham. 
Registre-se que para as professoras essas ações foram positivas e inovadoras tanto do ponto de vista do planejamento, quanto da prática e dos ganhos para os alunos. Para favorecer este processo de reflexão da prática, no fórum foi solicitado que cada professora apontasse dois momentos das aulas: um que achasse positivo e outro "nem tanto". A seguir evidenciaremos o que as docentes constataram sobre a aula.

\begin{abstract}
Gostei da dinâmica da aula, a maioria das duplas recorreram à multiplicação, isso para mim foi um dos pontos positivos, nos mostra que a turma já percebe que existem situações em que essa operação é mais indicada. A participação deles foi muito boa, a ideia de realizar uma atividade utilizando a função social dos números e das operações ajudou bastante. Alguns alunos ainda demonstram dificuldades de refletir sobre algumas situações, como o cálculo final (valor total) e o troco. Acredito que essa dificuldade seja pela falta de atividades como esta, onde eles são colocados dentro do contexto, e não só para resolver uma situação em que ele não faça parte. Destacaria como ponto que nos desfavoreceu, o tempo que foi pouco para conclusão da atividade e avaliação da mesma junto à turma. [P1 - grifos nossos]
\end{abstract}

[...] fiquei encantada com a aula do dia $11 / 10$, realmente minhas crianças me surpreenderam, elas sempre conseguem se superar. Acredito que o fato de termos proposto situações reais do cotidiano tenha viabilizado este belo resultado. É certo que em alguns momentos demonstraram mais dificuldades, mas conseguiram reverter a situação gradativamente, mediante as intervenções. Obrigada a todos pela colaboração e a presença confortante da equipe. [P2 grifos nossos]

Evidenciamos, que as professoras percebem as dificuldades dos alunos no que se refere às operações com multiplicação, que ainda continuam tratando esta operação como uma adição sucessiva. Mais do que a avaliação e percepção do nível da aprendizagem discente, a proposta formativa com uso de tecnologias digitais oportunizaram às professoras reflexão sobre elementos de sua prática que podem suscitar mudanças futuras no sentido de otimizá-la. Percebemos isso, em especial, quando as professoras comentam sobre os aspectos que desfavoreceram as aulas propostas, como é o caso da falta de tempo para desenvolver a atividade completa. A este respeito vale uma análise sobre o próprio processo de integração das tecnologias digitais na dinâmica da sala de aula. A medida que as tais recursos chegam à escola se torna praticamente impossível trabalhar nesse atual modelo de currículo, engessado e com aulas estanques.

Além disso, destacamos nas falas das professoras a satisfação com o trabalho colaborativo entre elas e os pesquisadores. Esse processo formativo, pautado na aprendizagem colaborativa com suporte computacional, contribuiu para as professoras vislumbrarem ganhos à sua prática docente e desenvolvimento profissional na medida em avaliam a experiência de maneira positiva e vantajosa em diversas dimensões. Esse é o caso quando P1 observa que quando contextualizam suas aulas os estudantes conseguem compreender melhor o conteúdo estudado. O uso do OA Supermercado Virtual, ao simular uma situação matemática real, contribui para o desenvolvimento da aula e a aprendizagem discente acerca dos conceitos explorados. Nesse sentido, à medida que as professoras compartilham em ambiente virtual um fato importante acontecido em sala de aula, elas reconstroem e, ao mesmo tempo, fazem uma reflexão de sua própria prática, consolidando assim a construção de um saber produzido e que não é previamente determinado. Trata-se, na verdade, de um saber que é construído na ação. 
Baseando-se nesta análise, evidenciamos as vantagens de se trabalhar na perspectiva teórica da aprendizagem colaborativa com suporte computacional. Tal concepção de aprendizagem fundamenta-se na teoria sociointeracionista de Vygotsky (2003), pois possibilita aos sujeitos propor e discutir conceitos e organizar ideias ao longo do processo educativo, com o diferencial do suporte computacional. Dessa maneira, é possível dizer que os participantes do processo educativo ensinaram e aprenderam mutuamente, mediado pelas tecnologias digitais.

Para ratificar se as professoras se apropriaram da proposta formativa colaborativa, no segundo fórum propusemos o debatemos sobre a proposta de formação docente em rede. Este fórum teve um caráter teórico, onde discutimos sobre os elementos presentes no texto: Aprendizagem colaborativa com suporte computacional: uma proposta para formação de professores. A partir da leitura e das práticas que tínhamos vivenciando questionamos que elementos as professoras gostariam de destacar, e quais as possibilidades e limitações dessa perspectiva. A seguir observamos o relato da professora $\mathrm{P} 1$ :

Gostei bastante do texto, é bem esclarecedor para quem ainda não conhecia o teor do Projeto UCA, ressalta a importância do uso das tecnologias digitais tendo um computador na sala de aula, destacaria a dinâmica, que deixa de ser eventual e passa a ocorrer com mais frequência, tornando-se habitual e proporcionando melhoria na qualidade da educação, uma vez que novas experiências podem ser adquiridas e o acesso às informações é maior. Uma das dificuldades que eu citaria é a também aprendizagem dos professores, a mudança de paradigmas torna alguns professores resistentes ao uso das tecnologias digitais. Isso pode pôr em risco um pouco o foco do uso do laptop em sala, que é aprender pela interação com o ambiente virtual, desenvolver competências que se tornaram praticamente exigências atualmente na nossa sociedade. $O$ professor precisa estar aberto a mudanças e disposto a praticá-las, uma nova ferramenta com a prática antiga não funcionará de forma tão satisfatória. [P1 - grifos nossos]

Constatamos que a partir do texto estudado a professora evidenciou que com esta mudança de paradigma o professor também torna-se um sujeito que deve aprender. Isso ainda tem uma certa resistência pois herdamos um modelo de escola que o professor é o detentor do conhecimento. Todavia, com a chegada das tecnologias digitais esse paradigma se exclui, nesse contexto o docente tem que estar aberto a mudanças para ressignificar sua prática. Convém destacar que a professora P2 não fez nenhum comentário sobre o texto estudado. Esta posição reforça a concepção de que acesso às ferramentas tecnológicas e cursos de formação não são suficientes para uma mudança da postura docente ante tais recursos em favor do desenvolvimento profissional. Estamos vivenciando um processo de mudança cultural e que certamente não acontece de forma repentina. Todavia isto não implica em negar a necessidade de mudanças na formação e na concepção das tecnologias digitais na educação.

$\mathrm{Na}$ aprendizagem colaborativa com suporte computacional, a ideia de coletividade é bastante evidente, pois um indivíduo ajuda o outro para que alcance um objetivo. Identificamos nessa própria dinâmica a necessidade contínua de colocar os professores e seus pares em contato com as tecnologias digitais para o seu desenvolvimento profissional. No caso dos laptops educacionais, um dos potenciais desses instrumentos é o de possibilitar a aprendizagem a partir da interação em rede, desenvolvendo competências e habilidades exigidas para a formação de professores no contexto da Cibercultura. 
Na relação entre teoria e prática, percebemos a teoria embasando a prática docente em sala de aula, devendo sempre estar presente nos momentos de formação do professor. Assim, evidenciamos que é necessário compreender a teoria para saber no que ela pode contribuir ou não na prática. Alguns professores costumam relatar que a teoria não se aplica na prática, ou que uma é diferente da outra. Já alguns teóricos se referem que a prática está esvaziada de teoria. Em nossa concepção uma não existe sem a outra, ou seja, ambas são inseparáveis. A proposta formativa apresentada oportuniza essa contínua relação de teoria refletida na prática, de forma colaborativa, entre professores, a partir de tecnologias digitais.

\section{CONSIDERAÇÕES FINAIS}

No contexto da Cibercultura, os sujeitos podem se constituir como autores dos processos comunicativos, incluindo aqueles mais diretamente relacionados ao ensino e à aprendizagem a partir das tecnologias digitais e sua interação no ciberespaço. Elencamos como exemplos o surgimento da $\mathrm{EaD}$ e mais recente dos $\mathrm{MOOC}$ como um espaço próprio às práticas de construção e desenvolvimento de criatividade coletiva, que favorece uma maior diversidade de atos cognitivos de forma que seus participantes podem interagir de modo aberto e com acesso gratuito.

Todavia, este cenário de possibilidades educacionais desenvolve-se em um movimento ainda marcado por práticas culturais centradas na hierarquia de emissão e recepção. Nos casos analisados neste trabalho as falas das participantes indicam que elas têm um perfil de usuárias de tecnologias digitais, este fato pode favorecer à experiências de colaboração com suporte computacional. Nessa perspectiva, consideramos a formação docente como fundamental para atuar no contexto da cibercultura.

Os ambientes online para o ensino e aprendizagem podem favorecer práticas de criação, autonomia e aprendizagem social em rede. Assim, práticas autênticas dos atores no ciberespaço, onde os professores-autores se apropriam de elementos que relacionam aos temas estudados, socializam o conhecimento e discutem sobre a formação docente. Tais práticas abrem novas perspectivas de ensino e de aprendizagem em um contexto que demanda crescentemente a efetiva participação dos sujeitos e maior interação com os demais participantes envolvidos nesses ambientes.

No ambiente colaborativo online escolhido para esta pesquisa as professoras refletiram sobre a prática docente em Matemática e se fundamentaram teoricamente do conceito de aprendizagem colaborativa com suporte computacional. Por fim, esta mudança de paradigma oportuniza que professores aprendam colaborativamente e experimentem o mesmo com seus alunos. Nesta perspectiva, o docente deixa de ser o detentor do saber e o processo de ensino e aprendizagem torna-se uma relação dialética. Nesse contexto os docentes devem estar abertos para ressignificarem suas práticas em sala de aula.

\section{AGRADECIMENTOS}

Nossos agradecimentos aos bolsistas de iniciação científica do Grupo de Pesquisa Matemática e Ensino (MAES) - Francisca Wellingda Leal da Silva, Paulo César da Silva Batista e Thaynara Dias Martins - que contribuíram significativamente para o desenvolvimento desta pesquisa. 


\section{REFERÊNCIAS}

1. BARRETO, M. C. Desafios aos pedagogos no ensino de Matemática. In: SALES; J. A. M. de; BARRETO, M. C., NUNES, J. B. C.; NUNES, A. I. B. L.; FARIAS, I. M. S. de; MAGALHÃES, R. de C. B. P. Formação e Práticas Docentes. Fortaleza: EdUECE, 2007, p. 243-254.

2. BRASIL. Princípios orientadores para o uso pedagógico do laptop na educação escolar. Brasília: MEC, 2007.

3. BORBA, M. C.; MALHEIROS, A. P. dos S.; ZULATTO, R. B. A. Educação a distância online. 2.ed. Belo Horizonte: Autêntica, 2008.

4. CASTELLS, M. A era da informação: economia, sociedade e cultura. São Paulo: Paz e Terra, v. $1,1999$.

5. CHAGAS, I. Trabalho Colaborativo Condição Necessária para a Sustentabilidade das Redes de Aprendizagem. In: M. M. (Dir.). Redes de aprendizagem. Redes de conhecimento. Lisboa: Conselho Nacional de Educação, 2002.

6. KENSKI, V. M. Tecnologias e tempo docente. Campinas, SP: Papirus, 2013. - (Coleção Papirus Educação).

7. LEMOS, A. Cibercultura: tecnologia e vida social na cultura contemporânea. 5. Ed. 2010.

8. LÉVY, P. Cibercultura. São Paulo: Editora 34, 1999.

9. LIMA, M. S. L. A formação contínua do professor nos caminhos e descaminhos do desenvolvimento profissional. (Tese de doutorado) São Paulo: Faculdade de Educação, USP, 2001.

10. MAIA, D. L. Ensinar Matemática com o uso de tecnologias digitais: um estudo a partir da representação social de estudantes de Pedagogia. 2012. 190p. Dissertação (Mestrado Acadêmico em Educação) - Universidade Estadual do Ceará, Fortaleza, 2012.

11. _ _ _ BARRETO, M. C. Formação do pedagogo na UECE para o ensino de Matemática com uso de TDIC. In: SANTOS, A. N. dos; ROGÉRIO, P. (Orgs.). Currículo: diálogos possíveis. Fortaleza: Edições UFC, 2013. pp. 317-339. - (Coleção Diálogos Intempestivos).

12. MESQUITA, O. A. de; CASTRO-FILHO, J. A. A construção de conteúdos educacionais digitais 2.0 sob o enfoque da múltipla autoria. In: Anais dos Workshops do Congresso Brasileiro de Informática na Educação. Rio de Janeiro: UFRJ, 2012.

13. NACARATO, A. M.; MENGALI, B. L. da S.; PASSOS, C. L. B. A Matemática nos anos iniciais do Ensino Fundamental: tecendo fios do ensinar e do aprender. Belo Horizonte: Autêntica, 2009.

14. OLIVEIRA, E. G. Educação a distância na transição paradigmática. Campinas: Papirus, 2003,143p. (Coleção Magistério: Formação e Trabalho Pedagógico).

15. PIMENTA, S. G. Formação de professores: identidade e saberes da docência. In: PIMENTA, S. G. (Org.). Saberes pedagógicos e atividade docente. 7a ed. São Paulo: Cortez, 2009. - (Saberes da docência).

16. PINHEIRO, J. L. Contribuições da Teoria dos Registros de Representação Semiótica na formação de professores de Matemática a partir de uma comunidade virtual. Texto de qualificação de Mestrado em Educação. Fortaleza: UECE, 2013.

17. SILVA, S. H.; BARRETO, M. C. Formação de professores que ensinam Matemática nos anos 
iniciais do Ensino Fundamental. In: FARIAS, I. M. S. de; NÓBREGA-THERRIEN, S. M.; CARVALHO, A. D. F. Diálogos sobre a formação de professores. Teresina: EDUFPI, 2013.

18. STAHL, G.; KOSCHMANN, T.; SUTHERS, D. Computer-supported collaborative learning: an historical perspective. In: R. K. Sawyer (Ed.). Cambridge handbook of the learning sciences. Cambridge, UK: Cambridge University Press, 2006.

19. VYGOTSKY, L. S. A formação social da mente: o desenvolvimento dos processos psicológicos superiores. São Paulo: Martins Fontes, 2003.

20. WARSCHAUER, M. Laptops and literary: learning in the wireless classroom. New York: Teachers College Press, 2006. 